
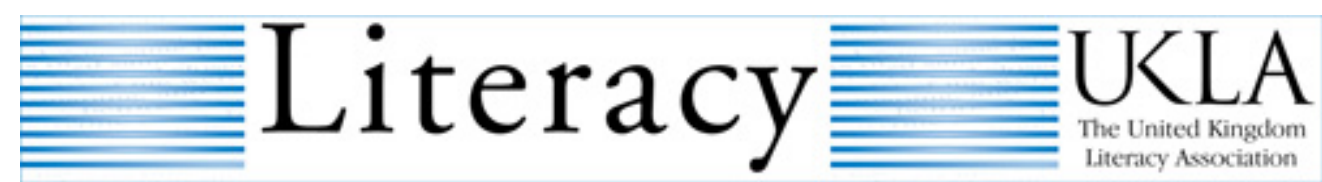

\title{
Literacies remaking public places: The Umbrella Movement of Hong Kong, 2014
}

\begin{tabular}{|r|l|}
\hline Journal: & Literacy \\
\hline Manuscript ID & LIT-OA-2019-023.R2 \\
\hline Keywords: & Creativity, Multimodality, Urban studies, Spatiality \\
\hline & $\begin{array}{l}\text { We approach Hong Kong's Umbrella Movement, also known as Occupy } \\
\text { Central, encountered in two days in November 2014 as an exemplar of } \\
\text { literacy as placemaking. As a contemporary city-based resistance } \\
\text { movement, the creation and subsequent resemiotization of literacy } \\
\text { artefacts was an important element of spatialized practice in asserting a } \\
\text { new and dynamic sense of citizenship. In their collaborative design, } \\
\text { shared commitment to certain values and expressions of political } \\
\text { resistance these occupation sites may be read as an instantiation of } \\
\text { Goodsell's (2003) concept of public space. The initial research site of } \\
\text { engagement gave rise to a dataset of photographs that the authors } \\
\text { examined together as discourses in place (Scollon \& Scollon, 2003), } \\
\text { informed by cultural knowledge of Hong Kong. Selecting two } \\
\text { photographs, we broaden out beyond the linguistic features of texts to } \\
\text { consider processes of creative semiotic remediation. We suggest that in } \\
\text { such placemaking activities the Umbrella Movement activists embodied } \\
\text { Giroux's (1992) concept of literacy as emancipatory practice. Finally we } \\
\text { make suggestions as to how this study might be connected to a critical } \\
\text { pedagogy of place (Mills \& Comber, 2013) }\end{array}$ \\
\hline
\end{tabular}

\section{SCHOLARONE ${ }^{\text {M }}$ Manuscripts}




\title{
Literacies remaking public places: The Umbrella Movement of Hong Kong, 2014
}

\begin{abstract}
We approach Hong Kong's Umbrella Movement, also known as Occupy Central, encountered in two days in November 2014 as an exemplar of literacy as placemaking. As a contemporary city-based resistance movement, the creation and subsequent resemiotization of literacy artefacts was an important element of spatialized practice in asserting a new and dynamic sense of citizenship. In their collaborative design, shared commitment to certain values and expressions of political resistance these occupation sites may be read as an instantiation of Goodsell's (2003) concept of public space. The initial research site of engagement gave rise to a dataset of photographs that the authors examined together as discourses in place (Scollon \& Scollon, 2003), informed by cultural knowledge of Hong Kong. Selecting two photographs, we broaden out beyond the linguistic features of texts to consider processes of creative semiotic remediation. We suggest that in such placemaking activities the Umbrella Movement activists embodied Giroux's (1992) concept of literacy as emancipatory practice. Finally we make suggestions as to how this study might be connected to a critical pedagogy of place (Mills \& Comber, 2013)
\end{abstract}

\section{Introduction}

“Occupy Central with Love and Peace" was planned in Hong Kong in 2013 to protest in the following year against the evident refusal of the Hong Kong government to guarantee fully democratic elections for its Chief Executive (Flowerdew \& Jones, 2016). Hong Kong, a former British colony, handed back to China in 1997 under the agreement, "One Country, Two Systems" believed itself to have democratic rights not existing in Mainland China. However, since at least the Tiananmen Square massacre in 1989, confidence that these democratic rights would be confirmed were hugely eroded as key dates for elections approached (Flowerdew, 2012; Garrett, 2013; Ma and Fung, 1999). On August 31, 2014 the Chinese government confirmed strict restrictions for the election of the Chief Executive in 2017 in Hong Kong, offering a limited slate of their handpicked candidates. (Pang, 2016).

In September 2014 student protesters boycotted classrooms and demonstrated; they were met by tear gas attacks by police. Gaining considerable public sympathy an 
occupation of three sites in the city persisted from late September to mid December 2014, involving many thousands of people (Flowerdew and Jones, 2016; Pang, 2016). This was often called the Umbrella Movement by its participants after a key symbol of the movement's peaceable character.

The Umbrella Movement in Hong Kong in 2014 was principally composed of students (Ortmann, 2015), including members of the Hong Kong Federation of Students associated with tertiary institutions. Joined by many secondary school students, affiliated to a movement called Scholarism, participants absented themselves from classes in universities, colleges and schools in order to participate passionately in a movement that aimed at radical change in governance (Chan, 2014). This movement, termed revolutionary by many participants, was not only about demanding a restructuring of their society and most particularly how it was governed but also sought from the beginning to enact its own precepts, to begin to show how society could be different. Common to other Occupy protests elsewhere on the globe, this involved radical and innovatory approaches to their own places of occupation and how they communicated these their burgeoning community identities through semiotic practices (Rojo, 2014a) .

In this paper we examine the remaking of place through literacy as emancipatory practice; we locate our endeavour in the socio-spatiality perspective outlined by Mills and Comber (2015, p. 91):

Spatiality in literacy studies includes the socio-material effects and relations of space-time in relation to literacy practices, textual artefacts, technologies for textual production, locations of literacy practices and texts, networks, social actors, and communities of practice.

Occupy movements around the world are fascinating phenomena in which to observe the rapid creation of a sense of community developing through spatialized practices that involve the use of literacy artefacts with common discursive themes and acts of resemiotization (Aboelezz, 2014). Focussing on this Hong Kong manifestation Lou and Jaworski (2016, p. 609) asserted, 'For many participants, the Umbrella Movement offered a glimpse and taste of Utopia, a sense of belonging to a community united by a shared ideal of democracy that drove them out of their homes to live together in the city streets for 81 days.'

Here we explore placemaking through literacy artefacts in the dynamic, powerful yet transitory spaces of the Umbrella Movement in Hong Kong as captured by the first author in two brief encounters in one week in November 2014. The transitory nature of the original data collection was approached positively as an opportunity for mediated discourse analysis (Scollon, 1998, 2001). Stressing discourse as mediated action in the world, Scollon uses the concept of site of engagement to point 
to any social action as a "real-time, irreversible, and unfinalizable... a unique moment in history." (Scollon, 2001, p. 4). The researcher is therefore very much part of the research, as every other participant bringing their "historical body" to bear (Scollon and Scollon, 2004). Her engagement and understanding were deepened through co-authorship with three eo-authors whose own histories have been long linked to-people from Hong Kong; indeed two of them travelled from Hong Kong to the UK just as the movement begun and were keen to pursue understandings of developing events-and its history. Next, however, we will introduce our perspective on public space, place-making and literacy artefacts before introducing our methodology, aim and data.

\section{Remaking of public spaces with literacy artefacts}

An influential way of conceptualising public spaces that lends itself to our approach is proposed by Goodsell, (2003). Drawing on the political and moral philosophy of Hannah Arendt, who argues that "public space is the sphere of public action essential to democratic citizenship" cited in (Goodsell, 2003, p. 362), he suggests a "generic definition of public space: a space-time continuum for connected and interactive political discourse." (Goodsell, 2003, p. 370). The significant features then of Goodsell's approach to public spaces are that:

- Public space is significant to democratic life;

- Physical public space should be conducive to interactions between people;

- Experience of public spaces is multi-layered; not just in embodied experience by citizens but also their access, e.g. through broadcast technologies or new media.

As Sheehy (2013) we draw on the discipline of human geography to comprehend literacies as among the resources available to people in specific places and examine the social processes involved in the creation of artifacts. Useful here is the third wave of Linguistic Landscapes (LL) scholarship, which takes a multimodal, participatory and relational understanding to the making of place (Blackwood, Lanza, \& Wodemariam, 2016). As Stroud, (2016: 4) proposes: “LLs are actively deployed by groups and individuals to enhance local engagement, sense of belonging, or acts of resistance, and to create conditions for new emotional geographies of place." There are different ways of conceptualising a distinction between space and place; we have learnt from Massey's (2004: 5) assertion that "space is a product of practices, trajectories, interrelations" and therefore relational; therefore places, understood as specific spaces with attributed identities, are also relational. Activities involved in making a space meaningfully public can be viewed as place-making. Visconti, Sherry, Borghini, and Anderson, (2010, p. 512) build on Goodsell's work to suggest that: "Places are fusions of human and natural order and are the significant centers of our immediate experiences of the world ...." Especially 
relevant for our engagement with the Umbrella Movement is their use of the term "'urban places'" to describe "appropriated sites where social interactions, sense of belonging, collective memories, and shared identities occur." (Visconti et al., 2010, p. 513).

Scollon and Scollon (2003) proposed the framework of geosemiotics, which they otherwise term "discourses in place" to emphasise the ways in which literacy artefacts such as publicly produced signs in the public environment are negotiated within human relationships, that are embodied, historically informed and inevitably material. Much of their research in geosemiotics was conducted in Hong Kong, so resonating in the first author's sensemaking at the time of data collection, although long before the Umbrella Movement's acts of place-making investigated here. We next turn then to an exploration of our methods that is necessarily woven into the nature of the opportunities for data collection and analysis as perceived by us.

\section{Methodology: The Umbrella Movement as a site of engagement}

The original conceptualisation of a site of engagement in research is "the real-time window that is opened through an intersection of social practices and mediational means (cultural tools) that make the action the focal point of attention of the relevant participants" (Scollon, 2002, pp. 3-4). It seems to us that this conception is complementary to contemporary relational materialist methodologies stressing the specificity of the researchers' constrained perceptions. Mediated discourse analysis requires that the researcher situates herself firmly within the analysis, rather than imagining herself as an objective observer. The researcher needs to enter into a "zone of identification" with participants in the field, recognising that her interactions constitute part of the data (Scollon and Scollon 2004). In relational materialist thinking, there is no possible separation: "We don't obtain knowledge by standing outside the world; we know because we are of the world." (Barad, 2007, p. 185).

In November $2014 \mathrm{~J}$, the first author, had the good fortune to find herself in Hong Kong during her second visit to the city at the time of the student protests known as the Umbrella Movement or Umbrella Revolution. These were manifested in three occupations of public areas and related activities. She spent approximately one and a half hours at the Mong Kok site on Sunday 2nd November and then three to four hours at Admiralty on Thursday 6th November. J decided to use the resources at hand to engage with the Umbrella Movement, its literacy artefacts and other "material-discursive-semiotic assemblings" (Burnett, Merchant, and Parry, 2017, p. 256) (henceforth assemblings) and to find what ways she could to deepen understandings later. 
With hindsight, her method at the time could be characterised in Kearns's (2016) terms as primary, uncontrolled observation. That is, she took the opportunity to interpret and recognise her own participation in the events as an embodied researcher. J understood that she was required to establish a zone of identification with the participants (Scollon \& Scollon, 2004). Her presence as a white European of a certain age could potentially have offered various standpoints. In certain moments when enabled, she rejected the potential standpoint of tourist; for example refusing a request to take a camera from a European man to photograph him against the background of the Mong Kok occupation. This moment, counter to everyday performances of politeness, caused her to realise that she wanted to occupy a more postcolonial perspective, intending a more egalitarian and supportive attitude towards the protesters. However as Howitt \& Stevens, (2016: 55) caution, “...despite good intentions, even what might be intended as postcolonial applied peoples' geography can still be exploitative, paternalistic, and ethnocentric in practice." J took opportunities to talk to participants when possible and also gave bags of provisions bought from a supermarket.

Other elements of Kearns's (2016) concept of primary, uncontrolled observation apply. Observations included seeing, listening and attunement to the soundscape. "Uncontrolled" means that the observations were not restricted to previously thought out criteria but were accompanied by distinct, if broad intentions, to collect materials to better understand the Umbrella Movement, and to ethical considerations. Photography was a central method; recognising that this activity is necessarily, including within the third wave perspective of LL, highly subjective. "Ways of seeing are historically geographically, culturally and socially specific"(Rose, 2007: 12). J's attention to ethical concerns at the time was ongoing and fluid (McKee \& Porter, 2008). Photographs of people were taken with permission where these singled out individuals; but otherwise decisions were made on the basis of general discussions and non-verbal cues. For example, some protesters were very clear about encouraging dissemination through all possible media; "Tell everyone you know on Facebook and Twitter." Some areas, such as provision tents were marked "No photography" and photographs were not taken where people were engaged in apparently private pursuits, such as sleeping, rather than demonstrating. She wrote up fieldnotes later on the same days and collected examples of media discourse in English.

On her return to the UK J brought initial thinking about the literacy artefacts in the Umbrella Movement to teaching an undergraduate course in Understanding Media in her Linguistics department to exemplify multimodality. This brought an offer of help from the third and fourth authors, G \& S who offered to help translate the Chinese texts visible in the images. Shortly afterwards J presented at two University research seminar groups (Literacy; Language, Ideology and Power). These brought further interest from the second author, $\mathrm{M}$, a postgraduate from Hong Kong and a 
more systematic approach to the research. $\mathrm{M}, \mathrm{G}$ and $\mathrm{S}$ were aware of the events in Hong Kong, frequently communicating with friends and family there about the events, and enthusiastic to be part of developing research, in the form of analyses, co-authoring and participating in the research meetings. There are considerable imbalances in our research together in that we bring different perspectives, experiences and knowledge bases to our work. The first author is in the privileged position of being a university lecturer and established in Literacy Studies; yet lacked the understandings of Hong Kong in far more than linguistic terms that the other authors were able to contribute. Together we are able to perform a collaboration that we recognise is partial and limited. "We take an engaged stance; how things are talked about is one of the major processes by which our worlds are constructed, legitimated, ratified, contested. Therefore, the analysis is a form of action in that world" (Scollon \& Scollon, 2004: 9).

We first looked separately, then together at the dataset of eighty photographs and decided consensually to select 20 as representative of the whole and yet distinctive from each other. Translations of visible Chinese texts were made, or improved by second, third and fourth authors. What we mean by "improved" is that ambiguities or complexities in meanings were made more visible and discussed. We each used our resources, linguistic and otherwise to annotate or comment on the assemblings identified in the photographs. Secondary research made use of online spaces associated with the Umbrella Movement and published research findings, while retaining a focus on exploring the dataset of original photographs. This final paper is the result of our collaborative analysis, reflection and writing together. Our research question emerged as: How did the protesters of the Umbrella Movement, as encountered at this specific time and space, remake place through literacy artefacts and other assemblings? Given the status of the protesting students and continuing pursuit of them by powerful institutions, we endeavoured to think through our research processes ethically. Thus we do not present in our photographic data portraits of occupying protesters themselves.

For this paper we decided to present our analyses of two photographs, selected as interesting, distinctive from one another and contributing effectively to the research question and illustrative of our methodology. We organise our analysis according to key themes that resonated repeatedly throughout the dataset of twenty photographs; but here we pick on just a few themes of each. "Yellow" for example could be discussed in respect of either photograph or most of the dataset, but we here discuss it in reference to just one of the photographs, although it could just as well be discussed with respect to the other.

\section{Findings}


The first selected photograph was taken on the periphery of the Mong Kok area occupied by protesters. This image is particularly dominated by paper-based literacy artefacts, the understanding of which is very much informed by geosemiotics, considering their situation in time and place. The second is no less representative of the dataset, but includes far fewer literacy texts. It is a photograph of the pedestrianised organic garden, which took the place of what is ordinarily a dual carriageway main road in Admiralty, an important business area. This is dominated by examples of what Pang (2016, p.156) terms "occupation arts....not made to support some political movement taking place elsewhere-they are themselves the sites of politics." This garden included the iconic and much photographed Umbrella Man statue. Both analyses fall very short of completeness but rather aim to bring out key findings in response to the research question.

\section{INSERT FIGURE 1 ABOUT HERE}

Figure 1 shows a photograph taken on Sunday $2^{\text {nd }}$ November at the Mong Kok occupation site with subsequent annotations by us to enable readers to immediately access some key translations. This was selected as an exemplar of literacy artefacts used at key points in the occupation sites; here at the entrance to the occupied site. It is a collection of signs and posters authored by multiple people. It forms part of a barrier by which this usually busy street has been blocked off and announces the beginning of the zone occupied by the protesters. The protesters' tents are just visible in the background. This particular collection of posters is heterogeneous in meaning and purpose, yet taken as a whole the display includes many themes of the Movement.

$\underline{\text { Umbrellas }}$ - here there is a physical umbrella (top left) and several other images of umbrellas. Umbrellas had become a symbol of the (largely) peaceful resistance of protesters to tear gas attacks from the police. At the top middle is an often reproduced digitally manipulated illustration of the Chinese president $\mathrm{Xi}$ Jinping; an official photograph of him holding a blue umbrella has been made yellow as if to suggest he might support the movement. His informal stance in such photos, exaggerated further through manipulation was often ridiculed as if suggesting he ought to be more dignified. Next to this is a message calling for the vote to be extended to the poor, countering the controversial suggestion from then Chief Executive CY Leung that one reason for resisting universal suffrage was that it would lead to dominance by the poor (Bradsher \& Buckley, 2014).

Yellow was the main colour of the movement; one of the posters displays a yellow ribbon, often associated with the protest movement. It is possible to find a link ascribed to the 1860s US Suffragette movement but we find more believable an association with the 1970s pop song "Tie a yellow ribbon". Yellow ribbons, whether in physical or virtual form became "small and highly transportable tokens of allegiance" to the Movement (Lou \& Jaworski, 2016, p. 612). It is also very possible 
that there might have been links to other resistance movements such as the protests in Italy in 2010, 2011 and 2012 studied by Barni \& Bagna, (2016). There, the fact that yellow had no tie to a political party assisted an association with peaceful protest in an egalitarian spirit.

Geosemiotics - the meanings of the texts themselves require to be understood in the context of being placed at this time, in this place and as a form of mediated action. The stance overall is united in a criticism of the leadership, especially CY Leung, the Chief Executive of Hong Kong from 2012 to 2017, particularly loathed by the protesters as well as a distrust of mainland China. Many texts index local ideological tensions, such as opposition to immigrants from mainland China, not necessarily an egalitarian stance, and the assertion that buying water from China is wasteful. The signs also link the occupation to other forms of action in the world, such as interactions with surrounding local shops (which were sometimes reported to fear a loss of trade) and a projection into the future, sharing information about legal protection that might serve to reassure people thinking of joining the protest but also anxious about it. That advisory message refers implicitly to phones as a technology the occupiers could use in communication with each other and others. Thus these signs act as part of a repertoire of ways the community communicates, including public meetings, study groups, online forums, through social media platforms etc.

Language ideologies - attitudes towards language in the Umbrella Movement are here manifested through the use of multilingualism and orthography. The use of English is common and often carries a wealth of connotations and associations. The word "Peace" in English for example appeared frequently, sometimes directly linked to John Lennon. Through this link Hong Kong people could demonstrate their breadth of global cultural references; at the same time the non-violent nature of their protest was an essential element of many occupiers and thus to be emphasised. Besides the content of the texts, the language and how it is expressed orthographically is of significance as a key element of expression of language ideologies (Sebba, 2013). The first language of the great majority of Hong Kong people is Cantonese but now almost everybody is taught and has to encounter officialdom in Mandarin. Also of significance is the writing system; in Hong Kong (as in Taiwan and Macau) many prefer Traditional Chinese and oppose a tendency by some to use Simplified Chinese. (Simplified Chinese was brought in by the PRC in the 1950s to boost the literacy rate.) Some people allege that the Hong Kong Government is increasingly using Simplified Chinese, while others assert that Traditional Chinese is still the main writing system of the Government and that it is not unusual to find three systems (Traditional Chinese, Simplified Chinese and English) together in official communications. Here a sense of identity as Hong Kongers is implied through the use of traditional characters on all posters such as the sign about the trio (referring to co- founders of the Occupy Central Occupation). This may be understood as self-identification of the community through differentiation, ie not using Simplified Chinese, or possibly as opposition. Scollon \& 
Scollon, (2003) found at the much earlier time of their study that this orthographic system symbolized modern Hong Kong life.

Hong Kong written Cantonese is distinctive in style, different for example from the written Cantonese used in other Cantonese-speaking regions such as Guangzhou. Some posters are written in Cantonese which is playing an increasingly important role in Hong Kong, a manifestation of "linguistically distinct, local identity, in this case that of a Hongkonger" (Lou \& Jaworski, 2016, p. 614).

\section{INSERT FIGURE 2 ABOUT HERE}

Figure 2 is a photograph taken on $6^{\text {th }}$ November at the Admiralty occupation site. This was selected as including literacy artefacts, yet also demonstrating how meaning-making in the construction of a dynamic place of resistance, goes beyond what are normally thought of as literacy texts into semiotic assemblings. Here as elsewhere throughout the three occupation sites there is creative semiotic remediation of artefacts and symbols.

Reconfiguration of space - Here a dual carriageway major thoroughfare through the business and governmental centre of the city has been blocked off by the occupation. The border between dual carriageways has been utilised as a boundary between two areas of the occupation. On the left are the tents in which the protesters stay, share refreshments and meet with each other and visitors. The right hand side of the barrier has been commandeered for an organic garden, enacting values of the Movement towards sustainability and wellbeing. As street artists, the protesters have contested official conceptions of what is appropriately placed here, what counts as dirt and what counts as clean, what counts as productive and pleasing and what as polluting and ugly (Visconti et al., 2010). The organic garden features small bits of equipment human agents need in order to turn this site into a new purpose and maintain it, including a small watering can and a bucket. Recycling is a shared value of the movement, here used glass bottles have been used to create an artwork in the foreground, the umbrella silhouette. The overall effect is what Rojo, (2014b) calls a "reterritorialization" of space in which protesters transform a public space into a manifestation of their own ideologies.

Assembling: Here we see a designed environment, in which it makes little sense to conceptually hive off the linguistic from the non-linguistic; everything contributes to the multimodal assemblage in which the protest enacts its positive values as well as its resistance to the political status quo. On the right of the picture is a relatively sinister artefact, a red object that resembles a Chinese coffin. The garden features a number of verbal texts, for example a blackboard features a loudly provocative message of resistance in English: "I don't need sex cuz the government 
FUCK me everyday." Here is a spatially oriented approach to literacy; in the words of Burnett (2015, p. 522): "literacies play a part in the production of spaces as well as being framed by them." The boldness of the message, located as it is in such a prominent site of the city, defines this as a site of resistance as much as it shouts temporary defiance. In the distant end of the garden a mobile artwork features outlines of yellow umbrellas; another instantiation of "itineraries of protest signage" (Lou \& Jaworski, 2016, p. 609) through which a communal identification with the Movement was forged. Next to that is a wooden sculpture of a man holding out a yellow umbrella. Attributed to a 22 year-old student calling himself "Milk" since its appearance on $5^{\text {th }}$ October 2014 it had attracted enormous attention at the site and online (Lou \& Jaworski, 2016, p. 635). This "Umbrella Man" artwork came to be perceived as embodying the desire for freedom and peace (Bradsher, 2014).

Site of engagement: Near the yellow umbrella, protesters on $6^{\text {th }}$ November were giving out yellow origami umbrellas. J took a small one but a student replaced it with a larger, asking her to tell everyone she knew about the movement on Twitter and Facebook, implicitly recognising Goodsell's (2003) recognition of the extended public space as salient to the democratic life of public spaces. As a mediated action, this contributed to "re-branding of the city with a small pool of recognizable trademark-like logos, slogans, and toponyms, as a critical step towards regaining the right to the city" (Flowerdew \& Jones, 2016, p. 624). These flowed in trajectories woven across the physical and digital, across mainstream and social media, from daringly hung banners to tiny symbols on student's backpacks.

\section{Discussion}

We propose that as evidenced through these analyses, the Umbrella Movement protesters were engaged in literacy as an emancipatory practice as adumbrated by Giroux (1992) in three aspects. First, he stresses that literacy can be a form of ideology critique that endeavours to "[make] visible the historically and socially constructed strengths and limitations of those places and borders we inherit and that frame our discourses and social relations. "In their choices of linguistic and orthographic preference the students index a specifically Hong Kong identity, in their relations to mainland China and their own multilingual, always dynamic heritage. In the discourses they make so materially visible they construct relations with other places on the globe such as sites of other Occupy and environmental movements.

Giroux's second aspect to literacy is as a form of "ethical address" that marks out boundaries of privilege and domination. "Borders signal both metaphorically and 
literally how power is inscribed differently on the body, culture, history, space, land, and psyche" (Giroux, 1992, p. 3). The border of the Mong Kok occupied zone was marked by literacy artefacts that in different ways addressed issues of power relations, with the local government, with mainland China, with other stakeholders of the street and yet also projecting a sense of the movement's members as vulnerable, with an outlook towards future arrests. The Admiralty site, as captured in the evidence of even this one photograph, was complex and intertextually rich in its addresses to power relations, from the major act of entirely reordering its usual functions to fine details of design. Drawing on the work of Arendt, Pang (2016, p. 157) argues of the Umbrella Movement, "It is from this interdependence between arts and politics that freedom arises." Both sites are simultaneously symbolically powerful yet fragile. Eventually the movement was very rapidly dismantled by police-backed bailiffs, acting ostensibly on behalf of the restoration of local business interests, accompanied by arrests of leaders.

Giroux's third aspect of literacy as emancipatory should not be forgotten either. This demands of researchers that we call into question established ways of conducting research, that we should re-examine our own locations within systems of knowledge production. This article has necessarily occluded the lengthy discussions we engaged in, especially as J worried about the severe time limits on the original data collection and her positionality as a British researcher. Hultman \& Lenz Taguchi (2010) assisted us to conceive as all acts of reading with photographs as being highly situated and relational. As embodied researchers with personal histories we craft "runners to other times and locations ... [that] are significant to how we make meaning in the here-and-now" (Burnett 2015, p. 523). Co-authoring this paper has been essential to us, not to then claim any kind of spurious objectivity, but rather to offer a particular kind of practice of ethnographic sensitivity in collective research, deepening our interpretations over time.

We have used these two photographs to underpin a proposal that what the students of the Umbrella Movement were achieving at these sites was an instantiation of Goodsell's (2003) conception of public spaces. In multi-levelled ways these occupation sites were committed to the pursuit of democracy: in their multiauthorship, design, shared commitment to a sustainable way of being and their expressions of political resistance to political oppression. The artefacts, whether considered as traditional literacy artefacts or more broadly semiotic assemblages, displayed considerable care at the level of detail, including in the creative resemiotizations that served to knit protesters together into a sense of new community. The interests of many different kinds of people associated with the protest were taken into account, such as the local shopkeepers of Mong Kok, people who might get arrested, and even projecting towards a future when people might be able to consume the fruits of the garden. We have contributed to the documentation of the urban placemaking of these "appropriated sites where social interactions, 
sense of belonging, collective memories, and shared identities occur" (Visconti et al., 2010, p. 513).

\section{Implications for practice}

There are various ways in which elements of this study could be used by literacy practitioners. Indeed, now two of us are active as teachers we hope that this study may contribute to the endeavours of place-conscious educators to engage with their students in a critical pedagogy of place (Mills \& Comber, 2013). The organic garden is an outstanding attempt to reterritorialize a small stretch of land previously, and soon, afterwards, used for such different purposes. Of course, this example took collective action on a large scale but many place-based pedagogic examples demonstrate the affective and inspirational aspects of participating in active reuse of spaces by students (Comber, 2016). Cities are in need of creative activity (Lefebvre, 1996: 147-151). In alignment with Lefebvre's valuing of the design of utopias, Pahl (2014) argues that futures thinking, involves close practices of noticing and can be stimulated by artistic representation or writing ethnographies, among other modes of action.

Our theoretical frame and methods also are potentially applicable elsewhere. Nexus analysis, geosemiotics and mediated discourse analysis, among other contributions by Scollon and Scollon beyond those referred to in this paper have been used fruitfully in countless studies. One of us, when investigating the dynamics of classroom interaction (reference withheld), made use of Massey's (2005) insights that space is the product of interrelations; the co-existence of distinct trajectories; and is always under construction.

\section{Conclusion}

The original site of engagement with these research sites was, as ever, "a unique moment in history" (Scollon 2001, p. 4). One impetus for our writing is to contribute to the unique history of Hong Kong and share with future generations a glimpse of its changing culture and how it became internationally famous for these events. and it is $\Theta$ Our knowledge of the transience of this occupation phase of the Umbrella Movement that brings us considerable emotional affect. We see too these assemblages as powerful instantiations of literacy in Giroux's $(1992$, p. 1) concept of literacy as emancipatory practice: "an enabling condition for forms of citizenship in which members of dominant and subordinate groups are offered subject-positions that address what it means to live in a society in which they have the opportunity to shape history in emancipatory terms rather than be the subject or object of its oppressive and colonizing practices." In semiotic remediation of words, symbols, 
artefacts, even the ground itself the Umbrella Movement performed intra actions with matter and meaning making (Barad, 2007) that we read as profoundly creative and ethical.

References

ABOELEZZ, M. (2014). The Geosemiotics of Tahrir Square: A study of the relationship between discourse and space. Journal of Language and Politics, 13.4, pp. 599-622. https://doi.org/10.1075/jlp.13.4.02abo

BARAD, K. (2007). Meeting the Universe Halfway: Quantum Physics and the Entanglement of Matter and Meaning. Durham, NC: Duke University Press.

BARNI, M., and BAGNA, C. (2016). 1 March - "A day without immigrants": the urban linguistic landscape and the immigrants' protest. In R. Blackwood, E. Lanza, \& H. Woldemariam (Eds.), Negotiating and Contesting Identities in Linguistic Landscapes (pp. 55-70). London and New York: Bloomsbury Academic.

BLACKWOOD, R., LANZA, E., and WODEMARIAM, H. (2016). Preface. In R. Blackwood, E. Lanza, \& H. Woldemariam (Eds.), Negotiating and Contesting Identities in Linguistic Landscapes (pp. xvi-xxiv). London: Bloomsbury Academic.

BRADSHER, K. (2014). New image of the Hong Kong protests: “Umbrella man." Retrieved September 26, 2016, from http://sinosphere.blogs.nytimes.com/2014/10/05/new-symbol-of-hong-kongprotests-umbrella-man/?_php=true\&_type=blogs\&_r=3

BRADSHER, K., and BUCKLEY, C. (2014, October 21). Hong Kong leader reaffirms unbending stance on elections. New York Times. Retrieved from https://www.nytimes.com/2014/10/21/world/asia/leung-chun-ying-hong-kongchina-protests.html?_r=2

BURNETT, C. (2015). (Im)materialising literacies. In J. Rowsell \& K. Pahl (Eds.), The Routledge Handbook of Literacy Studies (pp. 520-531). Abingdon, UK: Routledge.

BURNETT, C., MERCHANT, G., and PARRY, B. (2017). Past, present, future. In B. Parry, C. Burnett, \& G. Merchant (Eds.), Literacy, Media, Technology: Past, Present and Future (pp. 233-243). London: Bloomsbury Academic.

CHAN, J. (2014). Hong Kong's Umbrella Movement. The Round Table: The Commonwealth Journal of International Affairs, 103.6, pp. 571-580.

COMBER, B. (2016). Literacy, Place, and Pedagogies of Possibility. New York: Routledge. FLOWERDEW, J. (2012). Critical Discourse Analysis in Historiography: the case of Hong Kong's Evolving Political Identity. Basingstoke, UK: Palgrave Macmillan.

FLOWERDEW, J., and JONES, R. H. (2016). Occupy Hong Kong. Journal of Language and Politics, 15.5, pp. 519-526. https://doi.org/10.1075/jlp.15.5.01flo

GARRETT, D. (2013). Visualizing protest culture in China's Hong Kong: recent tensions over integration. Visual Communication, 12.1, pp. 55-70. 
https://doi.org/10.1177/1470357212447910

GIROUX, H. A. (1992). Literacy, pedagogy, and the politics of difference. College Literature, 19.1, pp. 1-11.

GOODSELL, C. T. (2003). The concept of public space and its democratic manifestations. American Review of Public Administration, 33.4, pp. 361-383. https://doi.org/doi:10.1177/0275074003254469

HOWITT, R., and STEVENS, S. (2016). Cross-cultural research: ethics, methods, and relationships. In I. Hay (Ed.), Qualitative Research Methods in Human Geography (4th ed., pp. 45-75). Don Mills, Ontario: Oxford University Press.

HULTMAN, K., and LENZ TAGUCHI, H. (2010). Challenging anthropocentric analysis of visual data: a relational materialist methodological approach to educational research. International Journal of Qualitative Studies in Education, 23.5, pp. 525-542. https://doi.org/10.1080/09518398.2010.500628

KEARNS, R. A. (2016). Placing observation in the research toolkit. In I. Hay (Ed.), Qualitative Research Methods in Human Geography (4th ed., pp. 313-333). Don Mills, Ontario: Oxford University Press.

LEFEBVRE, H. (1996). Writings on Cities. (E. Kofman \& E. Lebas, Eds.). Malden, MA: Blackwell Publishing.

LOU, J., and JAWORSKI, A. (2016). Itineraries of protest signage. Journal of Language and Politics, 15.5, pp. 609-642. https://doi.org/10.1075/jlp.15.5.06lou

MA, E. K. W., and FUNG, A. Y. H. (1999). Re-sinicization, nationalism and the Hong Kong identity. In C. Y. K. So \& J. M. Chan (Eds.), Press and Politics in Hong Kong - Case Atudies from 1967 to 1997 (pp. 497-528). Hong Kong: Hong Kong Institute of Asia-Pacific Studies, The Chinese University of Hong Kong.

MASSEY, D. (2004). Geographies of responsibility. Geografiska Annaler: Series B, Human Geography, 86.1, pp. 5-18. https://doi.org/10.1111/j.0435-3684.2004.00150.x MASSEY, D. (2005). For Space. London: SAGE Publications.

MCKEE, H., and PORTER, J. E. (2008). The ethics of digital writing research: a rhetorical approach. College Composition and Communication, 59.4, pp. 711-749.

MILLS, K. A., and COMBER, B. (2013). Space, place, and power: the spatial turn in literacy research. In K. Hall, T. Cremin, B. Comber, \& L. C. Moll (Eds.), International Handbook of Research on Children's Literacy, Learning, and Culture (pp. 412-423). Chichester, UK: Wiley-Blackwell.

MILLS, K. A., and COMBER, B. (2015). Socio-spatial approaches to literacy studies: rethinking the social constitution and politics of space. In J. Rowsell \& K. Pahl (Eds.), The Routledge Handbook of Literacy Studies (pp. 91-103). Abingdon, UK.

ORTMANN, S. (2015). The Umbrella movement and Hong Kong's protracted democratization process. Asian Affairs, 46.1, pp. 32-50.

PAHL, K. (2014). Materializing Literacies in Communities: The Uses of Literacy Revisited. London: Bloomsbury Academic.

PANG, L. (2016). Arendt in Hong Kong: Occupy, participatory art, and placemaking. Cultural Politics, 12.2, pp. 155-172.

ROJO, L. M. (2014a). Occupy: The spatial dynamics of discourse in global protest 
movements. Journal of Language and Politics, 13.4, pp. 583-598.

https://doi.org/10.1075/jlp.13.4.01mar

ROJO, L. M. (2014b). Taking over the Square: The role of linguistic practices in contesting urban spaces. Journal of Language and Politics, 13.4, pp. 623-652. https://doi.org/10.1075/jlp.13.4.03mar

ROSE, G. (2007). Visual Methodologies: An Introduction to the Interpretation of Visual Materials (2nd ed.). Thousand Oaks, CA: SAGE.

SCOLLON, R. (1998). Mediated Discourse as Social Interaction. London: Longman.

SCOLLON, R. (2001). Mediated Discourse: The Nexus of Practice. London: Routledge.

SCOLLON, R., and SCOLLON, S. W. (2003). Discourses in Place: Language in the Material World. London: Routledge.

SCOLLON, R., and SCOLLON, S. W. (2004). Nexus Analysis: Discourse and the Emerging Internet. London: Routledge.

SEBBA, M. (2013). Multilingualism in written discourse: approaches to the analysis of multilingual texts. International Journal of Bilingualism, 17.1, pp. 97-118.

SHEEHY, M. (2013). What does human geography have to do with classrooms? In K. Hall, T. Cremin, B. Comber, \& L. C. Moll (Eds.), International Handbook of Research on Children's Literacy, Learning, and Culture (pp. 400-411).

STROUD, C. (2016). Turbulent linguistic landscapes and the semiotics of citizenship. In R. Blackwood, E. Lanza, \& H. Woldemariam (Eds.), Negotiating and Contesting Identities in Linguistic Landscapes (pp. 3-18). London and New York: Bloomsbury Academic.

VISCONTI, L. M., SHERRY, J. F., BORGHINI, S., and ANDERSON, L. (2010). Street Art, Sweet Art? Reclaiming the "Public" in Public Place. Journal of Consumer Research, 37.3, pp. 511-529. https://doi.org/10.1086/652731 


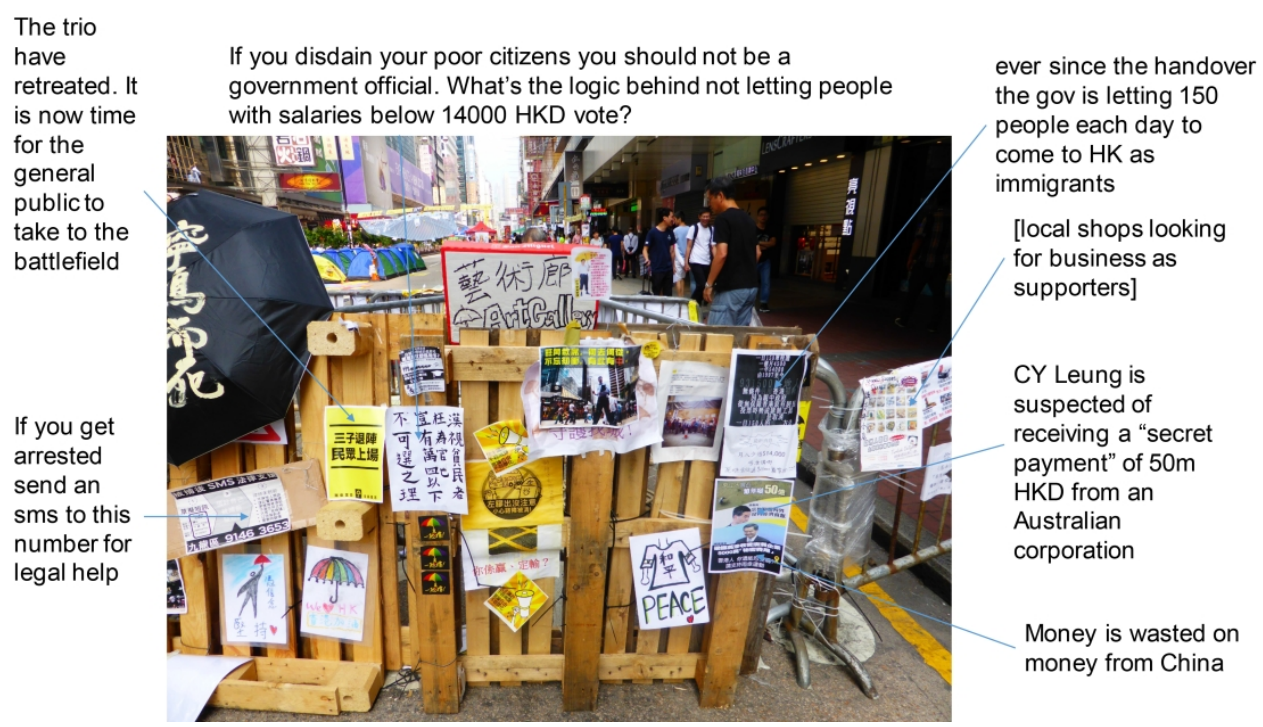

Sunday 2nd November 2014 Mong Kok 


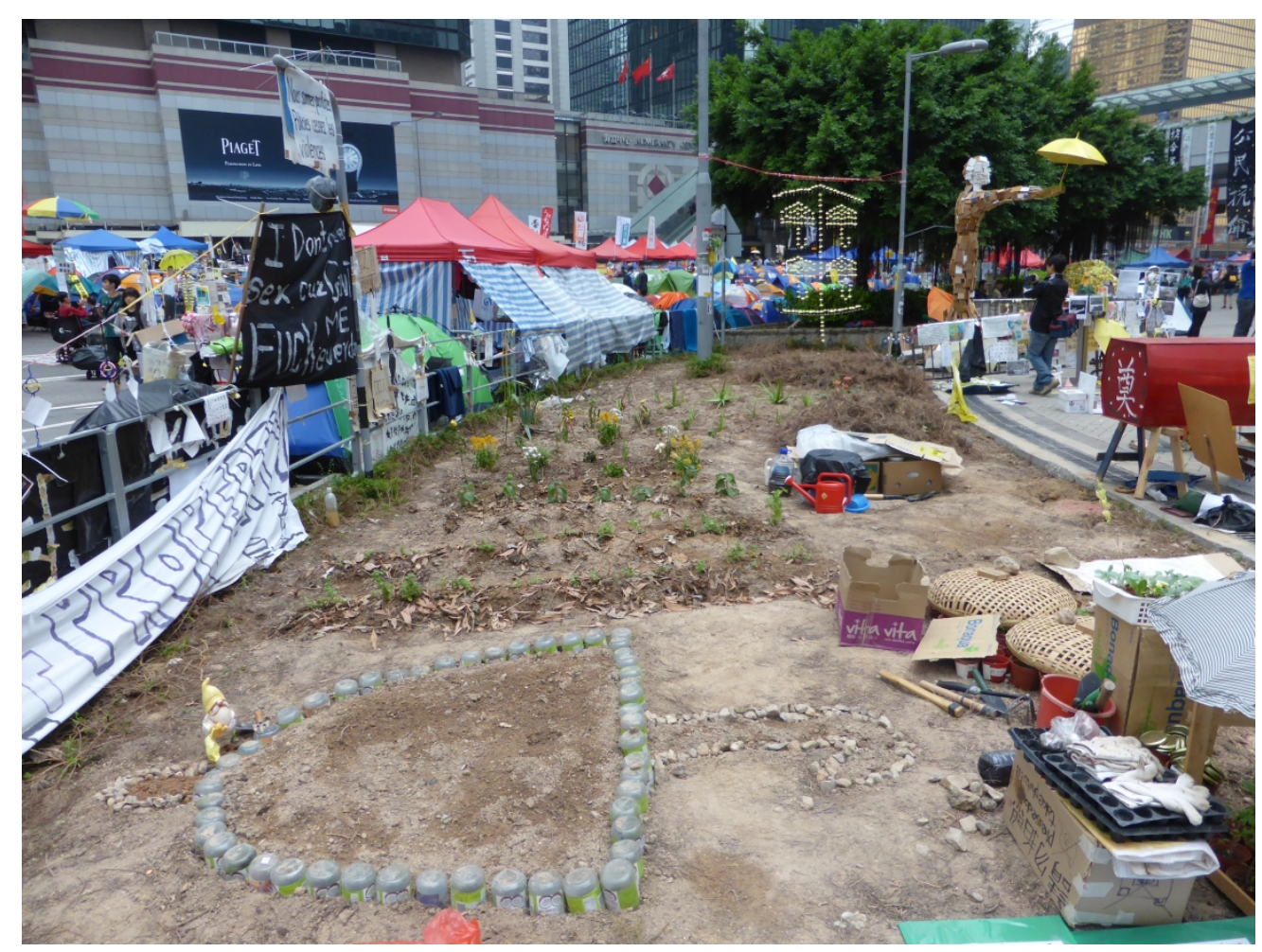

Thursday 6th November 2014 Admiralty $690 \times 518 \mathrm{~mm}(180 \times 180 \mathrm{DPI})$ 